\title{
Brief review: Theory and practice of minimal fresh gas flow anesthesia
}

\author{
Metha Brattwall, MD, PhD • Margareta Warrén-Stomberg, PhD • \\ Fredrik Hesselvik, MD, PhD · Jan Jakobsson, MD, PhD
}

Received: 16 March 2012/Accepted: 10 May 2012/Published online: 1 June 2012

(C) Canadian Anesthesiologists' Society 2012

\begin{abstract}
Purpose The aim of this brief review is to provide an update on the theory regarding minimal fresh gas flow techniques for inhaled general anesthesia. The article also includes an update and discussion of the practical aspects associated with minimal-flow anesthesia, including the advantages, potential limitations, and safety considerations of this important anesthetic technique.
\end{abstract}

Author contributions Jan Jakobsson is the main author of this review and has made substantial contributions to the conception and design of the manuscript and the acquisition and interpretation of data. Margareta Warrén-Stomberg, Metha Brattwall, and Fredrik Hesselvik critically revised the manuscript for important intellectual content.

Jan Jakobsson has provided lectures, has been acting medical advisor, and has taken part in advisory boards for MSD, Abbott, Baxter, Linde, and PaseIn. He has also received study grants from Abbott, MSD, Linde, and Baxter.

M. Brattwall, $\mathrm{MD}, \mathrm{PhD}$

Department of Anesthesiology \& Intensive care, Institution for clinical sciences, Sahlgrenska Academy, Gothenburg, Sweden

M. Warrén-Stomberg, $\mathrm{PhD}$

Institute of Health and care Sciences, University of Gothenburg/ the Sahlgrenska Academy, Gothenburg, Sweden

F. Hesselvik, MD, PhD · J. Jakobsson, MD, PhD ( $₫)$

Department of Anesthesiology and Intensive Care,

Danderyd Hospital, 18288 Danderyd, Stockholm, Sweden

e-mail: Jan.jakobsson@ki.se

J. Jakobsson, MD, PhD

Department of Anaesthesia \& Intensive Care, Institution for Physiology \& Pharmacology, Karolinska Institutet, Stockholm, Sweden
Principal findings Reducing the fresh gas flow to $<1$ $L \cdot \mathrm{min}^{-1}$ during maintenance of anesthesia is associated with several benefits. Enhanced preservation of temperature and humidity, cost savings through more efficient utilization of inhaled anesthetics, and environmental considerations are three key reasons to implement minimal-flow and closed-circuit anesthesia, although potential risks are hypoxic gas mixtures and inadequate depth of anesthesia. The basic elements of the related pharmacology need to be considered, especially pharmacokinetics of the inhaled anesthetics. The third-generation inhaled anesthetics, sevoflurane and desflurane, have low blood and low tissue solubility, which facilitates rapid equilibration between the alveolar and effect site (brain) concentrations and makes them ideally suited for low-flow techniques. The use of modern anesthetic machines designed for minimal-flow techniques, leak-free circle systems, highly efficient $\mathrm{CO}_{2}$ absorbers, and the common practice of utilizing on-line real-time multi-gas monitor, including essential alarm systems, allow for safe and costeffective minimal-flow techniques during maintenance of anesthesia. The introduction of new anesthetic machines with built-in closed-loop algorithms for the automatic control of inspired oxygen and end-tidal anesthetic concentration will further enhance the feasibility of minimal-flow techniques. Conclusions With our modern anesthesia machines, reducing the fresh gas flow of oxygen to 0.3-0.5 L.min ${ }^{-1}$ and using third-generation inhaled anesthetics provide a reassuringly safe anesthetic technique. This environmentally friendly practice can easily be implemented for elective anesthesia; furthermore, it will facilitate cost savings and improve temperature homeostasis.

\section{Résumé}

Objectif Le but de cet article de synthèse court est de fournir une mise à jour sur la théorie des techniques à bas 
debit de gaz frais pour les anesthésies générales par inhalation. L'article comporte également une mise à jour et une discussion sur les aspects pratiques de l'anesthésie à bas débit, notamment ses avantages, ses limites potentielles et des considérations sur la sécurité de cette importante technique d'anesthésie.

Constatations principales La réduction du débit de gaz frais en dessous de $1 \mathrm{~L} \cdot \mathrm{min}^{-1}$ au cours de la phase d'entretien de l'anesthésie est associée à plusieurs avantages. Un meilleur maintien de la température et de l'humidité, des économies grâce à une utilisation plus efficace des gaz anesthésiques inhalés et des considérations environnementales sont les trois principales raisons en faveur d'une mise en æuvre d'une anesthésie à bas débit et en circuit fermé, bien qu'elle présente des risques potentiels tels que les mélanges de gaz hypoxiques et une profondeur d'anesthésie insuffisante. Les eléments pharmacologiques pertinents de base doivent être pris en compte, en particulier la pharmacocinétique des anesthésiques inhalés. Les anesthésiques inhalés de troisième génération (sevoflurane et desflurane) sont peu solubles dans le sang et dans les tissus, ce qui facilite l'obtention rapide d'un équilibre entre la concentration alvéolaire et la concentration dans le site cible (le cerveau), les rendant parfaitement adaptés aux techniques à bas débit. L'utilisation de machines d'anesthésie modernes conçues pour les techniques à bas débit, les circuits fermés étanches, les absorbeurs de $\mathrm{CO}_{2}$ très efficaces, et l'habitude d'utiliser un analyseur Multi-gas ${ }^{T M}$ en temps réel sur le circuit, incluant des systèmes d'alarme essentiels, rendent les techniques à bas debit sécuritaires et rentables au cours de l'entretien de l'anesthésie. L'introduction de nouvelles machines d'anesthésie ayant des algorithmes intégrés pour circuits fermés permettant le contrôle automatique de l'oxygène inspiré et de la concentration télé-expiratoire d'anesthésique rendront les techniques à bas débit encore plus faciles à utiliser.

Conclusions Avec nos machines d'anesthésie modernes, la réduction des débits d'oxygène frais à 0,3-0,5 L.min ${ }^{-1}$ et l'utilisation d'anesthésiques inhalés de troisième génération, nous disposons de techniques d'anesthésie rassurantes et sécuritaires. Cette pratique respectueuse de l'environnement peut facilement être mises en place pour les anesthésies programmées. En outre, elle rendra les économies plus faciles et améliorera l'homéostasie de la température.

Despite considerable technological advances in modern anesthesia machines - many of which have unique design features rendering them fully compatible for minimal-flow and closed-circuit drug delivery - the use of minimal fresh gas flow techniques in clinical practice remains variable. The aim of this brief review is to provide an update on the basic physiology and pharmacology of minimal-flow techniques which are essential for the understanding and safe implementation of minimal fresh gas flow for inhaled general anesthesia. This article also includes an update and discussion on the practical aspects associated with minimal flow, including the advantages, potential limitations, and safety considerations.

The classification of gas flow rates into anesthetic circuits, as suggested by Baxter, ${ }^{1}$ is generally well accepted:

\begin{tabular}{ll}
\hline Metabolic flow & $<250 \mathrm{~mL} \cdot \mathrm{min}^{-1}$ \\
Minimal flow & $250-500 \mathrm{~mL} \cdot \mathrm{min}^{-1}$ \\
Low flow & $500-1000 \mathrm{~mL} \cdot \mathrm{min}^{-1}$ \\
Medium flow & $1-2 \mathrm{~L} \cdot \mathrm{min}^{-1}$ \\
High flow & $2-4 \mathrm{~L} \cdot \mathrm{min}^{-1}$ \\
Very high flow & $>4 \mathrm{~L} \cdot \mathrm{min}^{-1}$ \\
\hline
\end{tabular}

The benefits and feasibility of low-flow anesthesia have been suggested for nearly two decades. ${ }^{2}$ In 1995 , Baum and Atikenhead ${ }^{3}$ presented the following summary: "Although there are potential risks associated with low-flow anesthesia, modern anesthesia machines meet all the technical requirements for the safe use of low-flow techniques if they are used in conjunction with equipment for monitoring inhaled and exhaled gas concentrations; these monitors are already increasingly available and, in the near future, are likely to become an obligatory safety standard in many countries. For both economic and ecological reasons, the use of new inhalational anesthetics, with low tissue solubility and low anesthetic potency, can be justified only if the efficiency of administration is optimized by using lowflow anesthetic techniques."

The benefits of low-flow anesthesia include decreased use of inhaled agents, improved body temperature and humidity homeostasis, and reduced environmental pollution. The disadvantages include a potential for "physiologic gas contamination" with the theoretical risk for a hypoxic gas mixture. Furthermore, there is a potential risk for inadequate anesthetic gas concentration due to a dilution effect and/or the risk of misunderstanding the much slower response of anesthetic depth to changes in the vaporizer dial setting.

In this article, we address the benefits and risks of reduced fresh gas flow with a focus on delivery of oxygen at a flow rate of $250-500 \mathrm{~mL} \cdot \mathrm{min}^{-1}$ during maintenance of anesthesia. We also briefly review the physical basis of minimal-flow techniques and the related pharmacological essentials, followed by practical guidance on the safe 
implementation of minimal-flow anesthesia in routine clinical practice.

\section{Benefits from reducing fresh gas flow: accumulation of humidity}

Compressed medical gases are cold and dry. Reducing the fresh gas flow and subsequently recirculating the gas provides the benefit of conserving humidity and temperature. In 1990, Kleemann ${ }^{4}$ showed the benefits of preserving body temperature and humidity from breathing inspired gases from a low fresh gas flow. When comparing different fresh gas flows, he found that a minimal-flow technique $\left(0.5 \mathrm{~L} \cdot \mathrm{min}^{-1}\right)$ led to improvements in the heat $\left(28-32^{\circ} \mathrm{C}\right)$ and moisture $\left(20-27 \mathrm{mg} \mathrm{H} \mathrm{H}_{2} \mathrm{O} \cdot \mathrm{L}^{-1}\right)$ conditions of the anesthetic gases in the anesthesia systems. Branson et al. ${ }^{5}$ studied the effects of fresh gas flow on tracheal epithelium morphology and function as well as its impact relative to duration of anesthesia. These investigators observed that alterations in tracheobronchial structure and function result from exposure to dry gases, and furthermore, these changes were amplified according to increasing duration of exposure. Their results suggest that a minimum of $15 \mathrm{mg}$ $\mathrm{H}_{2} \mathrm{O} \cdot \mathrm{L}^{-1}$ is necessary to prevent these alterations. Baum et $a l^{6}{ }^{6}$ studied humidity and temperature during routine anesthesia with various fresh gas flows. They observed that adequate acclimatization was achieved with a conventional hose system and a minimal fresh gas flow. An absolute humidity of $17-30 \mathrm{mg} \mathrm{H}_{2} \mathrm{O} \cdot \mathrm{L}^{-1}$ was generally reached at the endotracheal tube's connector during the course of anesthesia. For the first cases of the day, there was a short delay of 15-30 min before reaching a humidity of at least $17 \mathrm{mg} \mathrm{H}_{2} \mathrm{O} \cdot \mathrm{L}^{-1}$. Bengtsson et al..$^{7}$ and Kleemann ${ }^{8}$ have also shown the simple preservation of humidity and temperature from the use of minimal-flow circle anesthesia. Recently, Bilgi et al. ${ }^{9}$ showed that respiratory function and also mucociliary clearance are better preserved with a lowflow anesthetic technique compared with high-flow anesthesia.

\section{Cost benefit from reducing fresh gas flow}

In several studies, inhalation anesthesia has been shown to be cost-effective and associated with lower drug costs. The drug-related costs have been shown to be lower compared with intravenous techniques, especially when taking drug waste into account. ${ }^{10-12}$ Although the cost of anesthesia constitutes only a small proportion of total costs associated with surgery, anesthetic drug expenditures have been a focus of increasingly important cost-containment efforts. Low-flow anesthesia is a simple method of reducing the consumption of volatile agents during inhalational anesthesia. ${ }^{13}$ Weiskopf and Eger et al. ${ }^{14}$ have described the impact of a significant reduction in anesthetic consumption and the subsequent cost reduction by reducing the fresh gas flow for the commonly used inhaled anesthetics, and this impact has also been shown in everyday clinical practice. ${ }^{15,16}$ Doolke et al ${ }^{17}$ conducted a study wherein the consumption of sevoflurane was measured during anesthesia for elective knee arthroscopy. Patients were randomized to receive one of three fresh gas flow rates, i.e., $1.5,3$, or $6 \mathrm{~L} \cdot \mathrm{min}^{-1}$, using sevoflurane and $\mathrm{O}_{2}: \mathrm{N}_{2} \mathrm{O}$ in a ratio of 1:2 after intravenous induction with fentanyl and propofol. A circle absorber system was used with a laryngeal mask airway device. The fresh gas flow rate had a profound effect on sevoflurane consumption. The measured sevoflurane consumption (standard deviation) more than doubled with each doubling of fresh gas flow [0.07 (0.03), $0.16(0.05), 0.41(0.12) \mathrm{mLmin}^{-1}$ of sevoflurane for gas flow $1.5,3$, and $6 \mathrm{~L} \cdot \mathrm{min}^{-1}$, respectively; $\left.P<0.01\right]$. The hourly sevoflurane-related cost decreased from 15.50 to 2.80 US\$ when reducing the fresh gas flow from 6-1.5 $\mathrm{L} \cdot \mathrm{min}^{-1}$. In an evaluation following the implementation of low fresh gas flow, Ryu et al. ${ }^{18}$ found a major impact on sevoflurane consumption. Five weeks before and 15 weeks after the implementation of a low fresh gas flow policy, the authors obtained the "anesthesia hours per bottle" of sevoflurane from the electronic medical records database. In the first five weeks after policy implementation, the anesthesia hours per bottle of sevoflurane increased by $73.7 \%$ (17.4 hr per bottle). In the following two consecutive five-week periods, anesthesia hours per bottle of sevoflurane increased by $16.5 \%$ and $30.1 \%$, respectively. During the entire 15 weeks after policy implementation, the anesthesia hours per bottle of sevoflurane increased by $38.3 \%$ (13.9 hr per bottle). Reducing the fresh gas flow to $<1 \mathrm{~L} \cdot \mathrm{min}^{-1}$ during shorter procedures has also shown similar beneficial effects. Lindqvist and Jakobsson ${ }^{16}$ found a further reduction in sevoflurane consumption from $0.26 \mathrm{~g} \cdot \mathrm{min}^{-1}$ to $0.17 \mathrm{~g} \cdot \mathrm{min}^{-1}$ with a fresh gas flow of 1 $\mathrm{L} \cdot \mathrm{min}^{-1}$ and $0.3 \mathrm{~L} \cdot \mathrm{min}^{-1}$, respectively.

\section{Workplace pollution: beneficial effects from reducing the fresh gas flow}

A matter of concern has been the potential negative health effects from workplace exposure to trace concentrations of airborne particles and gases. Most countries have adopted safety guidelines for ambient air quality in order to protect employee health. Several gas compounds are regulated, and occupational exposure limits are expressed by time weighted average exposure (TWA) during a working day; an eight-hour average exposure is expressed as a ppm limit. 
Concentrations are in the magnitude of $20 \mathrm{ppm}$ for the inhaled halogenated anesthetics and $25-100 \mathrm{ppm}$ for nitrous oxide. ${ }^{19}$ Modern operating rooms equipped with forced ventilation in combination with scavenging equipment on the anesthesia machine provide adequate workplace air quality. ${ }^{20,21}$ There are studies, however, which show unacceptably high ambient air concentrations of anesthetic agents. This has been associated, at least in part, with the negligence of anesthesia personnel who do not follow recommended routines and practices. ${ }^{22}$ Reducing the fresh gas flow has a potential beneficial impact on workplace air quality. The equipment must be securely safeguarded and leak-free, and any unnecessary leakages around the airway devices must be avoided in order to reduce the total amount of potent inhaled agents that may vaporize, circulate, and pollute the ambient air. In this way, low-flow anesthesia can also benefit the workplace environment.

\section{Beneficial effects from reducing fresh gas flow: lessening global pollution, greenhouse gases, and damage to the ozone layer}

The impact of inhaled anesthetics on the overall global environmental pollution has been debated for more than a decade. ${ }^{23-25}$ Although there is continued debate on the relative impact of halogenated anesthetic agents and their potential for ozone destruction and global warming, nevertheless, simple and safe measures to reduce their global release are undoubtedly relevant. Reducing the fresh gas flow has a major impact on the overall release of these compounds and thus should be promoted whenever feasible. Ryan and Nilsen ${ }^{26}$ estimated the carbon dioxide equivalent (CDE20) values to be 6,980 $\mathrm{g}$ for $1 \mathrm{MAC}$-hour at $2 \mathrm{~L} \cdot \mathrm{min}^{-1}$ fresh gas flow with sevoflurane. Avoiding $\mathrm{N}_{2} \mathrm{O}$ and reducing the fresh gas flow to $0.5 \mathrm{~L} \cdot \mathrm{min}^{-1}$ can significantly decrease the environmental burden from anesthetics. During short ambulatory procedures, Ekbom et al. ${ }^{15}$ found that the amount of sevoflurane consumed, vaporized, and subsequently released into the atmosphere at 1 MAC decreased from $0.66(0.07)$ to $0.48(0.05)$ $\mathrm{g} \cdot \mathrm{min}^{-1}$, a $27 \%$ reduction by reducing fresh gas flow from 2 to $1 \mathrm{~L} \cdot \mathrm{min}^{-1}$.

Another means to reduce the global impact of inhaled anesthetics is reclamation of exhaled gases using molecular sieve devices which are currently available (see: BlueZone ${ }^{\circledR}$ Technology @ http://bluezone.ca [accessed March 2012]). There are studies showing effective adsorption of halogenated agents with the use of high-silica zeolites. In minimal-flow anesthesia, Jänchen $e t a l .{ }^{27}$ found that $62 \%$ of the delivered desflurane was absorbed by the zeolite while $86 \%$ of the delivered desflurane was adsorbed in higher-flow anesthesia. Doyle et $a l^{28}$ found that a canister containing $750 \mathrm{~g}$ of the silica zeolite effectively removed $1 \%$ isoflurane from exhaled gases for periods of eight hours when the anesthetic was administered at a fresh gas flow of $3 \mathrm{~L} \cdot \mathrm{min}^{-1}$.

\section{Theoretical aspects and basic physiological and pharmacological considerations regarding low/minimal-flow anesthesia}

The uptake of oxygen from the inspired gas is related to physiological requirements, which are dependent on body size and metabolic needs. Appreciating that oxygen consumption during anesthesia under normal physiological circumstances is around $2-3 \mathrm{~mL} \cdot \mathrm{kg}^{-1} \cdot \mathrm{min}^{-1}$ in a healthy adult, the fresh gas flow can be reduced safely to $250-500 \mathrm{~mL}$ in adults with a body weight $<100 \mathrm{~kg}$. The oxygen consumption can be estimated by the formula $\mathrm{F}_{1} \mathrm{O}_{2}-\mathrm{FexpO}_{2}(\%) \times \mathrm{MV}(\mathrm{L}) \times 10$. For example, in a case with an inspired oxygen concentration of $35 \%$, an expired concentration of $31 \%$, and a minute ventilation of $5 \mathrm{~L} \cdot \mathrm{min}^{-1}$, the oxygen uptake is: $4 \times 5 \times 10=200 \mathrm{~mL}$ of oxygen per minute.

\section{Accumulation and mixing of endogenous gases in the circle breathing system during minimal-flow anesthesia}

There will be some accumulation and mixing of gases other than oxygen, carbon dioxide, and anesthetic agent within the circle breathing system.

Nitrogen constitutes a major part of ambient air and thus in the airways, and it needs to be considered in association with low/minimal-flow anesthesia. A 70-kg male has approximately $2.7 \mathrm{~L}$ of gaseous nitrogen; about $1.6 \mathrm{~L}$ is contained within the functional residual capacity (FRC), and about $1.1 \mathrm{~L}$ is dissolved in the water and fat compartments of the body. ${ }^{29}$ After a period of high-flow denitrogenation, $<1 \mathrm{~L}$ of nitrogen remaining in the body will be slowly exhaled and mix and accumulate in the gas space of a closed breathing system. ${ }^{30}$ Assuming a totally closed system, a patient's FRC of about $2 \mathrm{~L}$, and a breathing system volume of $3.6 \mathrm{~L}$, the theoretical maximal nitrogen concentration within the circle breathing system would be a magnitude of up to $18 \%(1 \mathrm{~L}: 5.6 \mathrm{~L})$. After a period of 6-8 min of denitrogenation, both Morita et al. ${ }^{31}$ and Bengtson et al. ${ }^{30}$ found that the average nitrogen concentration in the closed circuit increased from about $6 \%$ to a plateau of about $16 \%$. Dilution of gas in the circle system by nitrogen can be minimized by an effective denitrogenation of the gaseous compartment during 
induction. Shortening the denitrogenation period, i.e., nitrogen wash-out, will cause further accumulation of nitrogen within the circle system during anesthesia and result in a corresponding decrease in the oxygen and nitrous oxide concentration (if the fresh gas is an oxygennitrous oxide mixture). This accumulation and mixing may cause a dilution and theoretically lead to a hypoxic gas mixture. In theory, the nitrogen accumulation could also cause a dilution of nitrous oxide. The depth of anesthesia could therefore be diminished if based on the nitrous oxide component. However, if a potent halogenated inhalational agent, such as sevoflurane or desflurane, is used without nitrous oxide, nitrogen dilution will not jeopardize adequacy of anesthesia. The risk for a hypoxic gas mixture is minimal using oxygen as the sole part of the fresh gas flow, even if complete denitrogenation of the patient's FRC has not been effectively performed, e.g., shortening the period of preoxygenation and or incomplete tightness of the mask to face during oxygen breathing. The small amounts of air used for self-calibration in some sidestream multi-gas analyzers will have minimal, if any, clinically relevant impact on the circle gas composition in adult patients, especially given the return of these gases into the expiratory limb of the breathing circuit.

Water vapour is also a component of the circle system gas composition. The water vapour content will increase slowly during maintenance with low/minimal flow and subsequently dilute the oxygen partial pressure.

Methane is produced by intestinal organisms and absorbed; it is soluble in the body and partly exhaled, thus it will equilibrate with the circuit gases during low- and minimal-flow anesthesia. Intestinal methane production is variable, but the "endogenous production" is low. Low concentrations of methane (e.g., $5 \mathrm{ppm}$ ) may also be found in medical gases (1.2 ppm in atmospheric air), and the concentrations could accumulate during prolonged lowflow anesthesia. Blood methane levels of 2,000 ppm $(0.02 \%)$ have been recorded without apparent detrimental effect. Morita $e t$ al. also found that methane increased from $4.3 \mathrm{ppm}$ to stabilize at about $22.4 \mathrm{ppm}$, and acetone increased from $0.3 \mathrm{ppm}$ to $2.2 \mathrm{ppm}$ after two hours. ${ }^{31}$ During the same time period, the concentration of argon in a closed circuit in a hypothetical patient would increase up to $2.3 \%$ after two hours. Versichelen et al. ${ }^{32}$ found a minimal accumulation of carbon monoxide after $105 \mathrm{~min}$ in healthy patients. The theoretical risk for endogenous $\mathrm{CO}$ production and an increase in carboxyhemoglobin associated with severe hemolysis or massive transfusion should be considered. ${ }^{33}$

The increase in methane may influence the measurement of the concentration of anesthetic vapour. Mortier et al. ${ }^{34}$ showed that methane concentrations of 500-1,000 ppm may cause false halothane and isoflurane readings. Fortunately, the impact of methane on the readings of the third-generation inhaled anesthetics, sevoflurane and desflurane, is of no clinical importance. In 1999, Mortier et al. ${ }^{35}$ showed that the influence of methane at 3.3 microns wavelength was minimal for desflurane and sevoflurane measurements.

\section{Accumulation of exogenous noxious compound and exogenous gases}

It is important to ensure that accumulation of exogenous noxious compounds in the system does not occur due to the low-flow recirculation of gas. The composition of the $\mathrm{CO}_{2}$ absorber material is important to prevent sevoflurane from producing compound $\mathrm{A}$ and to prevent desflurane from producing $\mathrm{CO} .{ }^{36}$ Both the composition and hydration of the $\mathrm{CO}_{2}$ absorbent material are of importance, with some modern absorber materials having a minimal production of compound $\mathrm{A}$ and $\mathrm{CO}$, even with a fresh gas flow of $0.5 \mathrm{~L} \cdot \mathrm{min}^{-1}$. 37 There are safe $\mathrm{CO}_{2}$ absorbing materials other than soda lime; however, they are somewhat less efficacious. ${ }^{38}$ An absorbent, such as Amsorb ${ }^{\circledR}$, which does not contain a strong base, has been shown not to cause anesthetic degradation and formation of toxic products and is an obvious choice for low-flow anesthesia. ${ }^{39}$

Accumulation of "other exogenous gases" is not a clinical concern, keeping in mind the high purity of medical grade oxygen. However, if the oxygen used as fresh gas is from an onsite oxygenator, based on the technique of nitrogen elimination from ambient air, trace concentrations of gases in the ambient air should be considered, at least theoretically. If such oxygen is used, argon concentration may increase as much as $2 \%$. Argon is inert and has no toxic effects; however, argon dilution may have an effect on other gases, e.g., oxygen and other potent inhaled agents.

\section{Minimal fresh gas flow anesthesia: pharmacological aspects of inhaled anesthetics}

Knowledge of the pharmacokinetic characteristics of anesthetic drugs in the context of low-flow anesthesia is essential for safe and effective clinical application. At steady state, e.g., during stable maintenance of anesthesia, inhalational agent levels are in equilibrium from vaporizer to alveolus to blood, and finally to effect sites within the central nervous system. Much of an anesthetic, however, is provided outside of steady state conditions, such as induction, emergence, and any time that depth of anesthesia is adjusted. Low-flow anesthesia requires understanding of the basic pharmacology associated with inhaled anesthetics. Essential basic knowledge includes the kinetics associated 
with drug delivery, dialed gas concentration - fraction dialed concentration $(\mathrm{Fd})$, fraction of inspired anesthetic concentration (Fiaa), alveolar concentration assessed by means of the end-tidal anesthetic agent concentration (Etaa), and further uptake and distribution (Table 1). The timing involved with the distribution of inhaled anesthetic to various parts of the body, with a particular focus on the target organ, effect site, and requisite concentrations, must be understood (Table 2). During low-flow anesthesia, as for inhaled anesthesia in general, the kinetics, body uptake, and distribution are dependent on the agent used. Six major factors influence the uptake and distribution of anesthetics:

Partial pressure gradient of the anesthetic across the alveolar membrane

Alveolar ventilation

The blood-gas solubility coefficient of the anesthetic gas

Cardiac output

Basics aspects of organ perfusion and uptake of anesthetic gas in different body compartments

Central nervous system drug solubility

These basic pharmacokinetic variables are the same during low/minimal-flow techniques as they are during moderate or high fresh gas flow anesthesia; however, the amount of anesthetic, i.e., the anesthetic gas vaporized and "added to the circle gas", is decreased. The increase in gas concentrations/partial pressure is slower than during higher flows. When an increase in the depth of anesthesia is sought, the difference in the amount of anesthetic to add during wash-in, or at any time during maintenance of anesthesia, must be considered. There will be a discrepancy and delay between Fd and Fiaa. The alveolar concentration/partial pressure will subsequently rise more slowly. The arterial concentration will thus respond much more slowly to an increase in dialed concentration than during high flow. Subsequently, the effect site - central nervous system concentration will change less rapidly. The time constant, i.e., the time needed to achieve $63 \%$ of the targeted end point from one equilibrium concentration to the next, is inversely proportional to the fresh gas flow rate,

Table 1 Pharmacokinetics in low-flow anesthesia - variables of importance

Dialed concentration, concentration on the vaporizer - Fd

Inspired anesthetic agent concentration - Fiaa (for sevoflurane $\mathrm{Fi}_{\text {sevo }}$ )

End-tidal anesthetic agent concentration - Etaa (for sevoflurane

$\mathrm{Et}_{\text {sevo }}$ )

Alveolar anesthetic agent concentration - FA

Effect-site anesthetic agent concentration - Ce
Table 2 Adjusting effect-site concentration - depth of anesthesia

Bolus or "over pressure" - short burst of increased fresh gas flow and dial concentration 2-3 MAC (e.g., $30 \mathrm{sec}$ )

Increases Fiaa

Increases speed of rise in Etaa

Increases speed to raise effect-site concentration Ce

Increase anesthetic depth

and thus, it is longer with minimal-flow techniques. However, changes in the circle concentration of an inhaled anesthetic can be facilitated by changes in the rate of fresh gas flow and/or vaporizer "overpressure", providing a "bolus of inhaled agent" (Table 2).

\section{Benefits of third-generation inhaled anesthetics when used in minimal-flow anesthesia}

The low blood and tissue solubility of third-generation inhaled anesthetics is a desirable attribute when using these drugs in conjunction with reduced fresh gas flow. The difference in blood and tissue solubility will have an influence on the time needed for equilibration between the gas and blood concentrations and the effect site - central nervous system. The equilibrium between gas and blood is well-recognized from the classical wash-in and wash-out curves describing Faa/Fiaa. ${ }^{40}$ Thus, the increase in endtidal anesthetic gas is reduced when inhaled agents with lower blood to gas solubility are used (Fig. 1). The time needed to achieve clinical effect is, however, less well defined. Currently, no tools exist to measure effect-site concentration (Ceff) directly; therefore, surrogates must be used to provide an understanding of agent effect-site

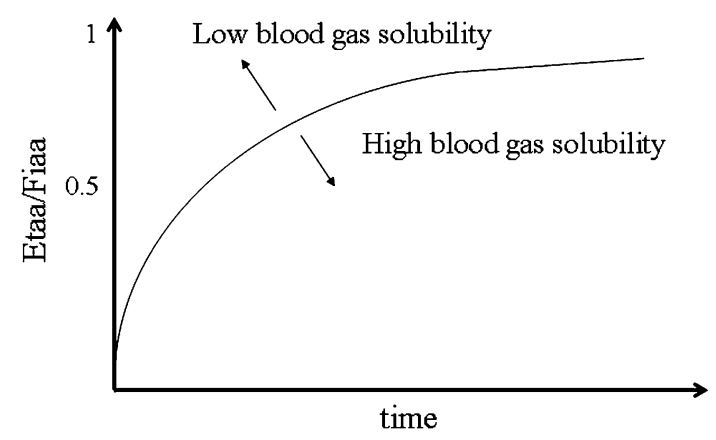

Fig. 1 Shown is the equilibration between inhaled anesthetic concentration and blood concentration as assessed by measuring the inspired fraction (Fiaa) and the end-tidal anesthetic concentration (Etaa) ratio. The lower the blood gas solubility, the faster is the equilibration, and vice versa. Thus, the wash-in period for the third generation inhaled anesthetics sevoflurane and desflurane, with blood gas solubility coefficients of 0.68 and 0.42 respectively, is more rapid than for isoflurane and earlier inhaled agents 
equilibration characteristics. Bispectral index (BIS) is one such surrogate that measures drug effect on electroencephalographic (EEG) suppression. When BIS effect is compared with Etaa, animal studies have shown that desflurane was taken up into the central nervous system 1.7 times faster than isoflurane and three times faster than halothane. ${ }^{41}$ The equilibration time constant $(\mathrm{ke} 0)$ reflects the partition coefficients for the blood-gas and blood-brain interfaces, which in turn depend on solubility. A higher ke0 value indicates faster equilibration from vaporizer to Ceff. Multiple studies have shown higher ke0 values for desflurane than for sevoflurane and isoflurane ${ }^{42,43}$ This means that an increase or decrease in Etaa using desflurane will result in a more rapid change in the depth of anesthesia.

Bispectral index measurements and $\mathrm{ke} 0$ values derived from pharmacokinetic modelling do not provide a full appreciation of inhalational agent equilibration. The value of ke0 also depends on the model chosen. A clinically more relevant measurement is the actual time to peak effect, i.e., the actual time from bolus administration until a clinically relevant effect, e.g., loss of response, readiness for insertion of a laryngeal mask airway device, and hemodynamic control of a stress response. Unfortunately, there are sparse time-to-effect data for inhalational agents in the literature. Existing data suggest that vital capacity induction with sevoflurane results in a shorter time to loss of consciousness than propofol (25 sec vs $44 \mathrm{sec}$, respectively) but results in a longer time to successful insertion of a laryngeal mask airway device (1.3 min vs $2.2 \mathrm{~min}$, respectively), findings since confirmed in other studies. ${ }^{44-47}$ When sevoflurane and isoflurane were compared in singlebreath induction (5\% vaporizer setting), the results showed equivalent time to loss of eyelid reflex $(75 \mathrm{sec}$ and $67 \mathrm{sec}$, respectively). ${ }^{48}$ The effect of dose on time to onset has been documented. A longer time to loss of consciousness was shown with tidal volume compared with vital capacity breathing ${ }^{49,50}$; likewise, an $8 \%$ vaporizer setting showed a faster time to onset than a $5 \%$ vaporizer setting. ${ }^{51}$ Due to its pungent nature, desflurane has been less well studied in inhalational induction. In the presence of fentanyl (up to $2 \mu \mathrm{g} \cdot \mathrm{kg}^{-1}$ ), incremental vaporizer increases (from 3.0$3.6 \%$ ) in steps of $3 \%$ each two to three breaths resulted in loss of eyelid reflex in 2.0 (1.1) $\mathrm{min}$ and 2.6 (1.1) $\mathrm{min}$ for desflurane in oxygen air and desflurane in oxygen/nitrous oxide, respectively. ${ }^{52}$

Studies are sparse on time to effect, control of depth of anesthesia, and hemodynamic effect during anesthesia, and there are no studies explicitly evaluating hemodynamic controllability during low/minimal-flow fresh gas flow. Experience with medium to high flow shows more rapid and precise control with desflurane. Bennett et al. ${ }^{53}$ found that desflurane allowed for more rapid control of blood pressure response to surgical stimulus (median $2 \mathrm{~min}$; range 1-12 $\mathrm{min}$ ) than isoflurane (median $6 \mathrm{~min}$; range 1-12 $\mathrm{min} ; P=0.011$ ), and the desflurane group required $30 \%$ fewer incremental anesthetic increases than the isoflurane group (1.8 vs 2.5, respectively; $P=0.016)$ to control increased systolic blood pressure. In 90 American Society of Anesthesiologists' physical status I-III patients undergoing lower abdominal procedures, Avramov et al. ${ }^{54}$ evaluated the effects of the fresh gas flow rate and the anesthetic technique on the ability to control the acute hyperdynamic response to a specific surgical stimulus during surgery. Anesthesia was maintained initially with desflurane or isoflurane, 0.7 MAC concentrations at total fresh gas flow rates of either 1 or $3 \mathrm{~L} \cdot \mathrm{min}^{-1}$. In response to the surgical stimulation of skin incision and retropubic dissection, an increase in mean arterial pressure (MAP) $\sim 20 \%$ above the pre-incision baseline MAP value was followed by either a stepwise increase in the inspired concentration of the volatile anesthetic or the intravenous administration of a variable-rate infusion of esmolol. They found that desflurane was faster at controlling hemodynamic response to painful stimulation at 1 as well as $3 \mathrm{~L} \cdot \mathrm{min}^{-1}$ fresh gas flow. At $1 \mathrm{~L} \cdot \mathrm{min}^{-1}$, the average time to control the MAP was significantly shorter with desflurane [17 (12) $\mathrm{min}$ ] than with isoflurane [29 (16) min], with $60 \%$ of the patients in the isoflurane group requiring rescue therapy. De Baerdemaeker et $a l .{ }^{55}$ studied fifty morbidly obese patients undergoing laparoscopic gastroplasty who received BIS-guided sevoflurane or desflurane anesthesia in combination with a remifentanil target-controlled infusion. Intraoperative hemodynamic stability and BIS control were measured. They found that overall hemodynamic control was better when using desflurane. It should be pointed out that these studies were not performed with a minimal fresh gas flow.

\section{Practical aspects of low-flow anesthesia}

\section{Essential equipment}

Low- and minimal-flow anesthesia can be easily implemented with modern anesthesia machines and monitoring equipment. A basic requirement is a circle breathing system with the following essential components: carbon dioxide absorber (a soda lime canister), two unidirectional valves, a fresh gas opening, a Y-piece to connect to the patient, a reservoir bag, a relief valve, and low-resistance interconnecting tubing (Fig. 2). Of course, the reservoir bag may be any form of "bag in bottle system" within an anesthesia machine capable of providing pressure support or controlled ventilation. The circle system needs to be tight and leak-free. As part of routine practice, leakage should be controlled before the start of anesthesia. 


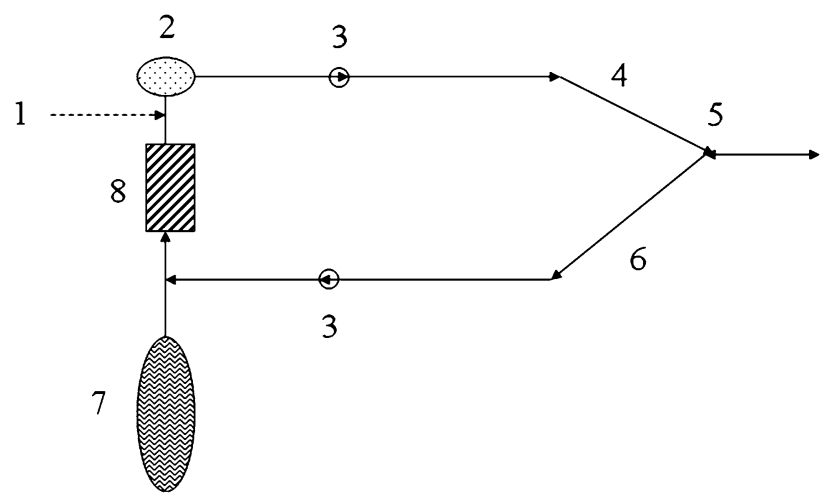

Fig. 2 Circle system essential component, 1. Fresh gas flow inlet, 2. Pressure release valve - "pop-off valve", 3.One way valve, 4. Inspiratory limb, 5. Y-piece, 6. Expiratory limb, 7. Gas reservoir (bag or belly), $8 . \mathrm{CO}_{2}$ absorber

The multi-gas monitoring equipment measuring inspired and expired end-tidal gas concentrations is a basic requirement. The $\mathrm{F}_{\mathrm{I}} \mathrm{O}_{2}$ must be measured on-line and the alarm must be set at an appropriate level in order to avoid a hypoxic gas mixture. Continuous measure of oxygen saturation with pulse oximetry, $\mathrm{SpO}_{2}$, is an essential requirement during low flow as well as during anesthesia in general. Both inspired and end-tidal anesthetic gas concentrations should be displayed; the end-tidal age-adjusted MAC multiple is a beneficial feature. The gas sampled by sidestream monitors should be compensated or fed back to the circle system, thus reducing the loss of gas due to the sampled volume. Mainstream multi-gas monitors that do not require gas sampling are also now available. ${ }^{56}$ Ventilation must be measured by capnography; inspired as well as end-tidal carbon dioxide should be measured. The importance of a properly functioning and charged $\mathrm{CO}_{2}$ absorber is a basic requirement, and the $\mathrm{F}_{\mathrm{I}} \mathrm{CO}_{2}$ should be evaluated in order to ascertain the functionality of the soda absorbing capacity.

Induction of anesthesia

Intravenous induction of anesthesia for either sevoflurane or desflurane, or inhaled induction (for sevoflurane) and securing of the airway should be done in a conventional manner following preoxygenation and application of routine monitors. More complete denitrogenation is easily achieved by administration of high flow for the period of a few minutes following induction of anesthesia.

\section{Maintenance of anesthesia}

Fresh gas composition may consist of oxygen, oxygen in air, or oxygen/nitrous oxide. Baum et al. described safe and effective low- and minimal-flow anesthesia using desflurane as the primary anesthetic and an oxygen/nitrous oxide combination as the fresh gas mixture. ${ }^{57}$ The use of nitrous oxide may be seen as somewhat more complicated, considering the need for more vigilant control of circle gas composition. The effect of nitrogen being released from the body stores and subsequently accumulating and diluting both the inspired oxygen and nitrous oxide needs to be considered. An alternative and potentially safer technique is to use oxygen or oxygen air only, avoiding the risk for dilution of the oxygen concentration by both nitrogen and nitrous oxide. The use of oxygen as the sole fresh gas essentially eliminates the risk for a hypoxic gas mixture. The use of a potent inhaled anesthetic as sole anesthetic avoids the risk of inadequate depth of anesthesia caused by nitrous oxide dilution. Decrease in oxygen concentration is slow during minimal flow and allows prolonged lag time before any potential for ensuing hypoxia. Routine use of inspired oxygen monitoring with appropriate alarms and the routine use of pulse oximetry $\left(\mathrm{SpO}_{2}\right)$ is essential to ensure proper oxygenation.

\section{Potential beneficial therapeutic effects associated with higher oxygen concentration during anesthesia and surgery}

The oxygen flow rate must be adequate to achieve and maintain adequate oxygenation; the gas mix in the inspiratory limb of the circle $\mathrm{F}_{1} \mathrm{O}_{2}$ must be adjusted in order to maintain adequate oxygenation $\left(\mathrm{SpO}_{2}\right)$. The use of sole oxygen for the fresh gas flow may end up in a $\mathrm{F}_{1} \mathrm{O}_{2}$ of $>30-40 \mathrm{vol} \%$. The risks associated with higher oxygen concentration during short periods of time, less than 8-12 $\mathrm{hr}$, are minor. ${ }^{58,59}$ It has been suggested that the use of a higher oxygen concentration has the beneficial effect of reducing the risk for postoperative nausea and vomiting (PONV). The meta-analyses of the effect of a high oxygen fraction on the occurrence and severity of PONV are not conclusive, but no negative effects have been reported in these studies. ${ }^{60,61}$ The potential beneficial impact of reducing the risk for surgical site infection (SSI) has been suggested, but likewise, this has not been proven conclusively. ${ }^{62-64}$ Research suggests that supplementing the patient with oxygen could facilitate improved healing by enhancing bacterial killing and angiogenesis, reducing surgical site infection rates, and increasing wound tensile strength. ${ }^{65}$ The independent role of increased $\mathrm{F}_{1} \mathrm{O}_{2}$ on surgical site infection in clinical practice is not entirely clear, ${ }^{66}$ but the studies conducted with a higher oxygen fraction $\left(\mathrm{F}_{\mathrm{I}} \mathrm{O}_{2}\right.$ 0.8) have not shown adverse effects on pulmonary function. ${ }^{67}$ 
Wash-in of the inhaled agent

There are various techniques for the introduction of the inhaled anesthetic. In general, they all follow the same sequence: nitrogen wash-out, a period of higher flow rate in combination with a high vaporizer setting for initial saturation, and subsequent reduction of fresh gas flow and adjustment of the vaporizer to maintain the desired Etaa. The wash-in, i.e., the saturation of the gaseous compartment, is dependent on the initial fresh gas flow and the vaporizer setting. In 1997, Mapelson ${ }^{68}$ described a theoretical model for the wash-in of halogenated anesthetics in conjunction with low-flow anesthesia. This model showed that an initial rotameter setting at $3.5 \mathrm{~L} \cdot \mathrm{min}^{-1}$ and a vaporizer setting of 3 MAC (age-adjusted concentration $18 \%$ desflurane for an adult patient) desflurane were able to increase the end-tidal concentration to $1 \mathrm{MAC}$ within one minute. Furthermore, if the fresh flow was set at $1 \mathrm{~L} \cdot \mathrm{min}^{-1}$, the dialed setting needed to be reduced to 1.5 MAC and further to 1.2 MAC at ten minutes. However, if the fresh gas was reduced to $250 \mathrm{~mL} \cdot \mathrm{min}^{-1}$, the vaporizer setting needed to be reduced to $2 \mathrm{MAC}$ in order to maintain the 1 MAC end-tidal concentrations as a consequence of the dialed $v s$ inspired discrepancy. The theoretical model was tested by Ip-Yam et al. ${ }^{69}$ The aim of their study was to increase the end-expired partial pressure of the inhalational agent (Etaa) to 1 MAC as quickly as practicable and then to keep it constant. They studied 90 adult patients undergoing elective tonsillectomy under general anesthesia who were randomly allocated to one of three groups $(n=30)$ to receive isoflurane, sevoflurane, or desflurane in oxygen. Fresh gas flow and vaporizer settings were followed as specified by Mapleson in all cases except that the maximum setting for desflurane was 18\% (2.7 MAC instead of 3 MAC). Recordings of Etaa were made at one, two, three, four, five, seven, ten, 15, and $20 \mathrm{~min}$. They found that the mean values of Etaa exceeded 1 MAC by two minutes in all three groups and remained slightly above this value throughout a 20-min observation period. Thus, with the fresh gas flow initially set equal to the total ventilation and the fresh gas partial pressure set to 2-3 MAC, the endexpired partial pressure can be raised to $1 \mathrm{MAC}$ in one minute with desflurane and sevoflurane, $1.5 \mathrm{~min}$ with isoflurane, $2.5 \mathrm{~min}$ with enflurane, and four minutes with halothane.

Lindqvist and Jakobsson described the following simple technique. ${ }^{16}$ Patients were pre-oxygenated with $\mathrm{F}_{\mathrm{I}} \mathrm{O}_{2}$ (1.0) $3 \mathrm{~L} \cdot \mathrm{min}^{-1}$ by facemask for at least two minutes for nitrogen wash-out before induction. After intravenous induction, a laryngeal mask airway device was placed and fresh gas flow was set at oxygen $1 \mathrm{~L} \cdot \mathrm{min}^{-1}$. A sevoflurane vaporizer was set at $8 \%$, and the fresh gas was kept at $1 \mathrm{~L} \cdot \min ^{-1}$ for one minute. Subsequently, fresh gas flow was adjusted and reduced to oxygen $0.7 \mathrm{~L} \cdot \mathrm{min}^{-1}, 0.5$ $\mathrm{L} \cdot \mathrm{min}^{-1}$, or $0.3 \mathrm{~L} \cdot \mathrm{min}^{-1}$. After induction, ventilation was assisted when needed, but patients were allowed to return to spontaneous breathing. The dial vaporizer setting was adjusted in order to achieve an end-tidal sevoflurane concentration of $1.2 \mathrm{vol} \%$. Time to reach an $\mathrm{Et}_{\text {sevo }}$ of $1.2 \%$ varied $3.6,2.5,1.5$, and $1.8 \mathrm{~min}$ for a fresh gas flow of 0.3 , $0.5,0.7$, and $1 \mathrm{~L} \cdot \mathrm{min}^{-1}$, respectively. A similar scheme was suggested by Eriksson and Bredbacka ${ }^{70}$ but with a somewhat longer period for saturation at a fresh gas flow of a combination of $0.2 \mathrm{~L} \cdot \mathrm{min}^{-1}$ of oxygen and 0.5 $\mathrm{L} \cdot \mathrm{min}^{-1}$ of air before reducing the flow to $0.2 \mathrm{~L} \cdot \mathrm{min}^{-1}$ of oxygen during maintenance, and their method was also shown most effective. With these simple schemes using sole oxygen or oxygen/air for fresh gas and a potent inhaled anesthetic in adequate end-tidal concentration, both safe and adequate $\mathrm{F}_{\mathrm{I}} \mathrm{O}_{2}$ and anesthetic depth can be achieved. An important safety consideration is the need for a proper understanding of the physiochemical and pharmacological properties of the inhaled anesthetics and the subsequent discrepancy between high- and minimal-flow anesthesia in terms of the time needed to achieve and maintain end-tidal gas concentrations. Maintaining the end-tidal anesthetic agent concentration at or above 0.7 MAC is important in order to avoid awareness and risk for recall. Avidan et al. recently reported on Etaa monitoring in high-risk awareness patients. ${ }^{71}$ Maintaining anesthetic depth with Etaa of 0.7-1.3 MAC multiples was found to be reassuringly safe.

As soon as the fresh gas flow rate is less than the patient's minute ventilation, it is important to remember that rebreathing causes a discrepancy between concentration delivered by the anesthesia machine and that inspired by the patient. The dialed ( $\mathrm{Fd})$ and inspired Fiaa concentration will not be the same. This discrepancy between dial concentration and inspired gas concentration may be perceived as "lack of control" (Fig. 3). With low-flow gas

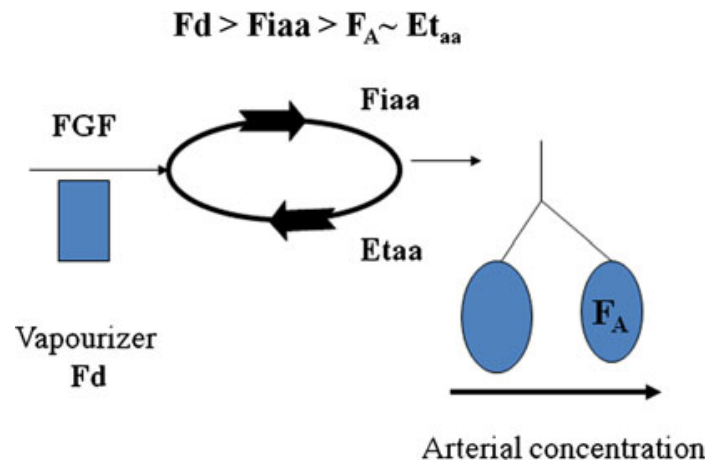

Fig. 3 Anesthetic concentrations, $\mathrm{Fd}=$ dialed concentration, concentration on the vaporizer, Fiaa $=$ inspired anesthetic agent concentration, Etaa = end-tidal anesthetic agent concentration, FA alveolar anesthetic agent concentration 
flow, there is a larger need to adjust and control not only Fd but also Fiaa and Etaa.

\section{Changing anesthetic depth}

Adjusting the effect-site concentration requires consideration of the longer time constant associated with the low/ minimal fresh gas technique. Thus, changes in the depth of anesthesia cannot be accomplished only by making minor alterations to the dialed vaporizer setting as during highflow anesthesia. A short inhaled bolus is required. A gas bolus provided by an increase in the flow rate and an increase of the vaporizer setting to 2-3 MAC is advisable under close observation of Fiaa and Etaa. A stepwise increase in Etaa of 0.3 MAC is a simple and safe technique. An inhalation bolus is administered by setting the vaporizer to $3 \mathrm{MAC}$ and increasing the fresh gas flow to $4 \mathrm{~L} \cdot \mathrm{min}^{-1}$ for $30 \mathrm{sec}$. Returning the fresh gas to minimal flow but keeping the vaporizer setting about $25 \%$ greater than the previous setting is a bolus technique shown to improve stability and avoid overcorrection. ${ }^{55}$ Likewise, reducing the anesthetic depth requires a major change in the vaporizer setting. A full closure of the vaporizer alone will lead to a slow decrease in Etaa; a bolus of fresh gas under observation of the Fiaa and Etaa is recommended if a more rapid reduction in anesthetic depth is required.

The volume of gas in the gaseous compartment, patient, circle system, connections, and attached equipment is followed easily by monitoring the filling/volume of gas in the reservoir (Fig. 2). Reduction of the reservoir gas volume is an indication of losses beyond that of the fresh gas flow. This may be caused by leakage from a number of places: the gas compartment, the tube connections, the airways (e.g., poorly sealed laryngeal mask airway device), or around the endotracheal tube cuff. A disproportionately low oxygen supply, i.e., less oxygen added to the fresh gas than uptake, is also a potential reason for loss of gas volume and a risk for development of a hypoxic gas mix. There is no need for "over-filling" of the reservoir as this gas will be released in the pop-off valve and "lost". There is a safety aspect in having an ascending reservoir and not a descending bellows in order to better ascertain adequate gas volume. Filling the reservoir without reaching peak pressure is thus "optimal".

Close surveillance of the inspired oxygen fraction $\mathrm{F}_{\mathrm{I}} \mathrm{O}_{2}$ and the volume in the reservoir is required in order to ensure the oxygen concentration and the volume of gas within the circle system. It is not only necessary to monitor the $\mathrm{F}_{\mathrm{I}} \mathrm{O}_{2}$, Fiaa, Etaa, and gas volume in the gaseous compartment, but it is also necessary to monitor and control the end-tidal carbon dioxide $\left(\mathrm{EtCO}_{2}\right)$. Inspired and $\mathrm{EtCO}_{2}$ concentrations should be maintained within physiological norms (or slightly higher than normal during laparoscopic procedures due to $\mathrm{CO}_{2}$ pneumoperitoneum). The $\mathrm{EtCO}_{2}$ is controlled by adjusting the alveolar ventilation; the inspired $\mathrm{CO}_{2}$ should also be observed as the $\mathrm{CO}_{2}$ absorber capacity is exhausted more rapidly during minimal-flow techniques.

End of surgery: planning for the emergence

The vaporizer dial setting can be reduced further and then closed toward the end of surgery as end-tidal drug concentration is commonly maintained with minimal flow rates during final suturing. The time constant allows for a slow change in the actual Etaa. With closed-circuit anesthesia, the time constant for gas elimination at $0.2 \mathrm{~L} \cdot \mathrm{min}^{-1}$ is about $30 \mathrm{~min}$. Thus, the vaporizer can be turned off for the last 15-20 min (or longer) while maintaining adequate alveolar drug concentrations. At the end of surgery, washout of the inhaled anesthetic is sought; wash-out is achieved by increasing the fresh gas flow rate to minute ventilation while monitoring the Etaa.

Improvements in inhaled anesthetic administration techniques

Nowadays, there are closed-loop controllers that act as "co-pilots" in clinical settings, providing safe and stable control of one or more aspects of anesthetic drug delivery under the supervision of a clinician. Liu et al. ${ }^{72}$ described a closed-loop controller for intravenous anesthesia. At present, there are anesthesia machines with a built-in controller for automated control of inspired oxygen and end-tidal anesthetic gas concentrations. In 2006, Schober and Loer reviewed the improvements in delivery techniques and the development in anesthetic machines. ${ }^{73}$ The Zeus ${ }^{\circledR}$ anesthesia machine by Dräger (Lübeck, Germany) relies on a classical circle system; however, the volatile anesthetics are delivered to the breathing circuit by means of a metering system for Direct Injection of Volatile Anesthetics (DIVA) rather than by vaporizers. ${ }^{\mathrm{A}}$ The machine can be used in a so-called auto-control mode where the inspiratory oxygen concentrations and targeted end-tidal anesthetic are automatically achieved and maintained by feedback-controlled closed-loop control algorithms. Saturated anesthetic vapour is injected directly from the vaporizing chamber into the circuit via a heated pipe, and the preset end-tidal concentrations are attained within a short time. The gas volume in the system is kept constant by adding fresh-gas to the circuit to maintain an endexpiratory pressure of 1 mbar in the breathing bag. A similar closed-loop control system, the Et Control, is an

\footnotetext{
$\overline{\mathrm{A}} \mathrm{http} / / / \mathrm{www} . d r a e g e r . c o m /$ local/products/zeus-ie/en/keyfacts/index. html.
} 
optional gas delivery mode for the fully digital Aisys ${ }^{\circledR}$ Carestation ${ }^{\circledR}$ from GE Healthcare. ${ }^{B}$ Intelligent built-in safeguard algorithms protect against over-delivery and under-delivery of anesthetic agent and hypoxia.

Contraindications to low-flow anesthesia

There are no absolute contraindications to utilizing low-flow anesthesia during elective general anesthesia. Keeping in mind the long time constants of minimal-flow techniques, it may not be optimal to use minimal-flow techniques in emergency cases or in medically complex patients where a rapid adjustment of the inhaled anesthetic concentration may be required. The use of minimal flow is a more challenging technique during mask anesthesia or whenever the airway is not sealed completely for other reasons.

There are a number of potential risks to acknowledge with minimal-flow anesthesia, including the possibility of accumulation of endogenous released gases, the potential for a build-up of carbon monoxide in heavy smokers, and in emergency cases, the possibility of exposure to products of combustion and the endogenously formed $\mathrm{CO}$ in conjunction with massive transfusion and/or hemolysis. Likewise, the risk for accumulation of acetone in poorly controlled diabetes or severely malnourished patients should also be considered. Finally, malignant hyperthermia, severe bronchial asthma, and septicemia would also be contraindications to using low-flow techniques.

\section{Conclusions}

With our modern anesthesia machines, reducing the fresh gas flow of oxygen to $250-500 \mathrm{~mL} \cdot \mathrm{min}^{-1}$ and using a third-generation inhaled anesthetic provide a reassuringly safe anesthetic technique. This environmentally friendly practice can easily be implemented for elective anesthesia; furthermore, it will facilitate cost savings and improve temperature homeostasis. Maintenance of anesthesia with fresh gas flow rates of $250-500 \mathrm{~mL} \cdot \mathrm{min}^{-1}$ provides several benefits. There are obvious economic as well as environmental advantages and a decreased risk of workplace contamination. The technique may avoid rapid fluctuations in inspired gas concentrations and improve the humidification and temperature homeostasis of the inspired gases. Concerns regarding patient safety may be the major factor for the somewhat slow introduction of minimal-flow anesthesia. There are no additional safety concerns regarding the use of higher flow rates when modern multigas monitors and pulse oximetry are the standard of care.

\footnotetext{
$\overline{\mathrm{B}}$ http://www.gehealthcare.com/euen/anesthesia/products/aisys/index. html.
}

The third-generation inhaled anesthetics, desflurane and sevoflurane, with their low blood and tissue solubility, promote the use of minimal-flow anesthesia by increasing the titratability of drug concentration at lower flow rates. The use of a potent inhaled anesthetic with appropriate end-tidal concentration as well as a minimal flow of oxygen virtually eliminates any concerns regarding dilution of the gas composition within the circle system and the subsequent risk for a hypoxic gas mixture or inadequate depth of anesthesia. During minimal-flow techniques, as with moderate-flow anesthesia, continuous monitoring of the inspired oxygen fraction, end-tidal anesthetic concentration, and the $\mathrm{CO}_{2}$ concentration are mandatory in order to ensure patient safety.

Conflicts of interest There are no further conflicts of interest associated with the writing of this brief review.

\section{References}

1. Baxter $A D$. Low and minimal flow inhalational anaesthesia. Can J Anaesth 1997; 44: 643-52.

2. Hargasser S, Mielke L, Entholzner E, Hipp R. Anesthesia with low fresh gas flow in clinical routine use (German). Anasthesiol Intensivmed Notfallmed Schmerzther 1995; 30: 268-75.

3. Baum JA, Aitkenhead AR. Low-flow anaesthesia. Anaesthesia 1995; 50(Suppl): 37-44.

4. Kleemann PP. The climatisation of anesthetic gases under conditions of high flow to low flow. Acta Anaesthesiol Belg 1990; 41: 189-200.

5. Branson RD, Campbell RS, Davis K, Porembka DT. Anaesthesia circuits, humidity output, and mucociliary structure and function. Anaesth Intensive Care 1998; 26: 178-83.

6. Baum J, Zuchner K, Holscher U, et al. Climatization of anesthetic gases using different breathing hose systems (German). Anaesthesist 2000; 49: 402-11.

7. Bengtson JP, Bengtsson A, Stenqvist O. The circle system as a humidifier. Br J Anaesth 1989; 63: 453-7.

8. Kleemann PP. Humidity of anaesthetic gases with respect to low flow anaesthesia. Anaesth Intensive Care 1994; 22: 396-408.

9. Bilgi M, Goksu S, Mizrak A, et al. Comparison of the effects of low-flow and high-flow inhalational anaesthesia with nitrous oxide and desflurane on mucociliary activity and pulmonary function tests. Eur J Anaesthesiol 2011; 28: 279-83.

10. Heidvall M, Hein A, Davidson S, Jakobsson J. Cost comparison between three different general anaesthetic techniques for elective arthroscopy of the knee. Acta Anaesthesiol Scand 2000; 44: 157-62.

11. Smith I, Terhoeve PA, Hennart D, et al. A multicentre comparison of the costs of anaesthesia with sevoflurane or propofol. Br J Anaesth 1999; 83: 564-70.

12. Dolk A, Cannerfelt $R$, Anderson RE, Jakobsson J. Inhalation anaesthesia is cost-effective for ambulatory surgery: a clinical comparison with propofol during elective knee arthroscopy. Eur J Anaesthesiol 2002; 19: 88-92.

13. Eger EI, White PF, Bogetz MS. Clinical and economic factors important to anaesthetic choice for day-case surgery. Pharmacoeconomics 2000; 17: 245-62. 
14. Weiskopf RB, Eger EI 2nd. Comparing the costs of inhaled anesthetics. Anesthesiology 1993; 79: 1413-8.

15. Ekbom K, Assareh H, Anderson RE, Jakobsson JG. The effects of fresh gas flow on the amount of sevoflurane vaporized during 1 minimum alveolar concentration anaesthesia for day surgery: a clinical study. Acta Anaesthesiol Scand 2007; 51: 290-3.

16. Lindqvist M, Jakobsson J. Minimal flow anaesthesia for short elective day case surgery; high vaporiser settings are needed but still cost-effective. Ambul Surg 2011; 17: 27-9.

17. Doolke A, Cannerfelt R, Anderson R, Jakobsson J. The effects of lowering fresh gas flow during sevoflurane anaesthesia: a clinical study in patients having elective knee arthroscopy. Ambul Surg 2001; 9: 95-8.

18. Ryu HG, Lee JH, Lee KK, et al. The effect of low fresh gas flow rate on sevoflurane consumption. Korean J Anesthesiol 2011; 60: 75-7.

19. Marx T. Pollution of the work environment by volatile anesthetics and nitrous oxide (German). Anasthesiol Intensivmed Notfallmed Schmerzther 1997; 32: 532-40.

20. Hall JE, Henderson KA, Oldham TA, Pugh S, Harmer M. Environmental monitoring during gaseous induction with sevoflurane. Br J Anaesth 1997; 79: 342-5.

21. Schebesta K, Lorenz V, Schebesta EM, et al. Exposure to anaesthetic trace gases during general anaesthesia: CobraPLA vs. LMA classic. Acta Anaesthesiol Scand 2010; 54: 848-54.

22. Lukaszewski M, Kubler A, Durek G. Spectrophotometric evaluation of nitrous oxide pollution in the work place of the anesthesiologic personnel in operating rooms (Polish). Pol Merkur Lekarski 2004; 17: 438-42.

23. Langbein T, Sonntag H, Trapp D, et al. Volatile anaesthetics and the atmosphere: atmospheric lifetimes and atmospheric effects of halothane, enflurane, isoflurane, desflurane and sevoflurane. Br J Anaesth 1999; 82: 66-73.

24. Parker NW, Behringer EC. Nitrous oxide: a global toxicological effect to consider. Anesthesiology 2009; 110: 1195.

25. Ishizawa $Y$. Special article: general anesthetic gases and the global environment. Anesth Analg 2011; 112: 213-7.

26. Ryan SM, Nielsen CJ. Global warming potential of inhaled anesthetics: application to clinical use. Anesth Analg 2010; 111: 92-8.

27. Janchen J, Bruckner JB, Stach H. Adsorption of desflurane from the scavenging system during high-flow and minimal-flow anaesthesia by zeolites. Eur J Anaesthesiol 1998; 15: 324-9.

28. Doyle DJ, Byrick R, Filipovic D, Cashin F. Silica zeolite scavenging of exhaled isoflurane: a preliminary report. Can J Anesth 2002; 49: 799-804.

29. Barton $F$, Nunn JF. Totally closed circuit nitrous oxide/oxygen anaesthesia. Br J Anaesth 1975; 47: 350-7.

30. Bengtson JP, Sonander H, Stenqvist O. Gaseous homeostasis during low-flow anaesthesia. Acta Anaesthesiol Scand 1988; 32: 516-21.

31. Morita S, Latta W, Hambro K, Snider MT. Accumulation of methane, acetone, and nitrogen in the inspired gas during closedcircuit anesthesia. Anesth Analg 1985; 64: 343-7.

32. Versichelen L, Rolly $G$, Vermeulen $H$. Accumulation of foreign gases during closed-system anaesthesia. Br J Anaesth 1996; 76: 668-72.

33. Ziemann-Gimmel P, Schwartz DE. Increased carboxyhemoglobin in a patient with a large retroperitoneal hematoma. Anesth Analg 2004; 99: 1800-2.

34. Mortier E, Rolly G, Versichelen L. Methane influences infrared technique anesthetic agent monitors. J Clin Monit Comput 1998; 14: 85-8.

35. Mortier E, Struys M, Versichelen L, Rolly G. Influence of methane on infrared gas analysis of volatile anesthetics. Acta Anaesthesiol Belg 1999; 50: 119-23.
36. Mazze RI. Composition of $\mathrm{CO}(2)$ absorbents. Anesth Analg 2001; 92: 1356-7.

37. Struys MM, Bouche MP, Rolly $G$, et al. Production of compound A and carbon monoxide in circle systems: an in vitro comparison of two carbon dioxide absorbents. Anaesthesia 2004; 59: 584-9.

38. Higuchi H, Adachi $Y$, Arimura S, Kanno M, Satoh T. The carbon dioxide absorption capacity of Amsorb is half that of soda lime. Anesth Analg 2001; 93: 221-5.

39. Kharasch ED, Powers KM, Artru AA. Comparison of Amsorb ${ }^{\circledR}$, sodalime, and Baralyme ${ }^{\circledR}$ degradation of volatile anesthetics and formation of carbon monoxide and compound $\mathrm{A}$ in swine in vivo. Anesthesiology 2002; 96: 173-82.

40. Yasuda N, Lockhart SH, Eger EI 2nd, et al. Kinetics of desflurane, isoflurane, and halothane in humans. Anesthesiology 1991; 74: 489-98.

41. Lockhart SH, Cohen Y, Yasuda N, et al. Cerebral uptake and elimination of desflurane, isoflurane, and halothane from rabbit brain: an in vivo NMR study. Anesthesiology 1991; 74: 575-80.

42. Rehberg B, Bouillon T, Zinserling J, Hoeft A. Comparative pharmacodynamic modeling of the electroencephalographyslowing effect of isoflurane, sevoflurane, and desflurane. Anesthesiology 1999; 91: 397-405.

43. Kreuer S, Bruhn J, Wilhelm W, Bouillon T. Pharmacokineticpharmacodynamic models for inhaled anaesthetics (German). Anaesthesist 2007; 56: 538-56.

44. Molloy ME, Buggy DJ, Scanlon P. Propofol or sevoflurane for laryngeal mask airway insertion. Can J Anesth 1999; 46: 322-6.

45. Siddik-Sayyid SM, Aouad MT, Taha SK, et al. A comparison of sevoflurane-propofol versus sevoflurane or propofol for laryngeal mask airway insertion in adults. Anesth Analg 2005; 100: 1204-9.

46. Ti LK, Chow MY, Lee TL. Comparison of sevoflurane with propofol for laryngeal mask airway insertion in adults. Anesth Analg 1999; 88: 908-12.

47. El-Radaideh KM, Al-Ghazo MA. Single breath vital capacity induction of anesthesia with $8 \%$ sevoflurane versus intravenous propofol for laryngeal tube insertion in adults. Saudi Med J 2007; 28: $36-40$.

48. Sloan MH, Conard PF, Karsunky PK, Gross JB. Sevoflurane versus isoflurane: induction and recovery characteristics with single-breath inhaled inductions of anesthesia. Anesth Analg 1996; 82: 528-32.

49. Shao G, Zhang G. Comparison of propofol and sevoflurane for laryngeal mask airway insertion in elderly patients. South Med J 2007; 100: 360-5.

50. Liu SJ, Li Y, Sun B, et al. A comparison between vital capacity induction and tidal breathing induction techniques for the induction of anesthesia and compound A production. Chin Med J (Engl) 2010; 123: 2336-40.

51. Topuz D, Postaci A, Sacan O, Yildiz N, Dikmen B. A comparison of sevoflurane induction versus propofol induction for laryngeal mask airway insertion in elderly patients. Saudi Med J 2010; 31 : 1124-9.

52. Wrigley SR, Fairfield JE, Jones RM, Black AE. Induction and recovery characteristics of desflurane in day case patients: a comparison with propofol. Anaesthesia 1991; 46: 615-22.

53. Bennett JA, Mahadeviah A, Stewart J, Lingaraju N, Keykhah $M M$. Desflurane controls the hemodynamic response to surgical stimulation more rapidly than isoflurane. J Clin Anesth 1995; 7 : 288-91.

54. Avramov MN, Griffin JD, White PF. The effect of fresh gas flow and anesthetic technique on the ability to control acute hemodynamic responses during surgery. Anesth Analg 1998; 87: 666-70.

55. De Baerdemaeker LE, Struys MM, Jacobs S, et al. Optimization of desflurane administration in morbidly obese patients: a 
comparison with sevoflurane using an 'inhalation bolus' technique. Br J Anaesth 2003; 91: 638-50.

56. Kilic M, Warren Stromberg M, Jakobsson J. Clinical performance of a novel main-stream anaesthetic end-tidal gas monitors during routine low flow anaesthesia. J Anesthe Clinic Res 2010; DOI: $10.4172 / 2155-6148.1000112$

57. Baum J, Berghoff M, Stanke HG, Petermeyer M, Kalff G. Lowflow anesthesia with desflurane (German). Anaesthesist 1997; 46: 287-93.

58. Brewis RA. Oxygen toxicity during artificial ventilation. Thorax 1969; 24: 656-66.

59. Demchenko IT, Welty-Wolf KE, Allen BW, Piantadosi CA. Similar but not the same: normobaric and hyperbaric pulmonary oxygen toxicity, the role of nitric oxide. Am J Physiol Lung Cell Mol Physiol 2007; 293: L229-38.

60. Rincon DA, Valero JF. Supplemental oxygen for the prevention of postoperative nausea and vomiting: a meta-analysis of randomized clinical trials (Spanish). Rev Esp Anestesiol Reanim 2008; 55: 101-9.

61. Orhan-Sungur M, Kranke P, Sessler D, Apfel CC. Does supplemental oxygen reduce postoperative nausea and vomiting? A meta-analysis of randomized controlled trials. Anesth Analg 2008; 106: 1733-8.

62. Qadan M, Akça O, Mahid SS, Hornung CA, Polk HC Jr. Perioperative supplemental oxygen therapy and surgical site infection: a meta-analysis of randomized controlled trials. Arch Surg 2009; 144: 359-66.

63. Brar MS, Brar SS, Dixon E. Perioperative supplemental oxygen in colorectal patients: a meta-analysis. J Surg Res 2011; 166 : 227-35.
64. Meyhoff CS, Wetterslev J, Jorgensen LN, PROXI Trial Group, et al. Effect of high perioperative oxygen fraction on surgical site infection and pulmonary complications after abdominal surgery: the PROXI randomized clinical trial. JAMA 2009; 302: 1543-50.

65. Chambers AC, Leaper DJ. Role of oxygen in wound healing: a review of evidence. J Wound Care 2011; 20: 160-4.

66. Canet J, Belda FJ. Perioperative hyperoxia: the debate is only getting started. Anesthesiology 2011; 114: 1271-3.

67. Staehr AK, Meyhoff CS, PROXI Trial Group. Inspiratory oxygen fraction and postoperative complications in obese patients: a subgroup analysis of the PROXI trial. Anesthesiology 2011; 114: 1313-9.

68. Mapleson $W W$. The theoretical ideal fresh-gas flow sequence at the start of low-flow anaesthesia. Anaesthesia 1998; 53: 264-72.

69. Ip-Yam PC, Goh MH, Chan YH, Kong CF. Clinical evaluation of the Mapleson theoretical ideal fresh gas flow sequence at the start of low-flow anaesthesia with isoflurane, sevoflurane and desflurane. Anaesthesia 2001; 56: 160-4.

70. Eriksson S, Bredbacka S. Better gas anesthesia technique better for environment, economics and patients. Systematic improvement work gave results (Swedish). Lakartidningen 2011; 108: 1190-2.

71. Avidan MS, Jacobsohn E, Glick D, BAG-RECALL Research Group, et al. Prevention of intraoperative awareness in a highrisk surgical population. N Engl J Med 2011; 365: 591-600.

72. Liu N, Chazot T, Hamada S, et al. Closed-loop coadministration of propofol and remifentanil guided by bispectral index: a randomized multicenter study. Anesth Analg 2011; 112: 546-57.

73. Schober P, Loer SA. Closed system anaesthesia-historical aspects and recent developments. Eur J Anaesthesiol 2006; 23: 914-20. 